\title{
Predominance of the basal type and HER-2/neu type in brain metastasis from breast cancer
}

\author{
Jochen Gaedcke ${ }^{1}$, Frank Traub ${ }^{1}$, Simone Milde ${ }^{1}$, Ludwig Wilkens ${ }^{1}$, Alexandru Stan ${ }^{1}$, \\ Helmut Ostertag ${ }^{2}$, Mathias Christgen ${ }^{1}$, Reinhard von Wasielewski ${ }^{1}$ and Hans H Kreipe ${ }^{1}$ \\ ${ }^{1}$ Institute of Pathology, Medizinische Hochschule Hannover, Hannover, Germany and ${ }^{2}$ Institute of Pathology, \\ Regionskrankenhaus Hannover, Hannover, Germany
}

\begin{abstract}
Although breast cancer is the second most common cause of central nervous system (CNS) metastases with a notable increase of incidence, only few studies on brain-metastasizing breast cancer are available. In this immunohistochemical and fluorescence in situ hybridization (FISH) study, metastases to the CNS $(n=85)$ and primary breast cancers, with known involvement of the CNS $(n=44)$ including paired primary and metastasized tumours $(n=23)$, were investigated retrospectively for the expression of oestrogen- $(E R)$ and progesterone(PR) hormone receptors, Her-2/neu, epidermal growth factor receptor (EGFR), Ki-67, and cytokeratins (CKs) 5/ 14. The majority of brain metastases were steroid hormone receptor negative (ER 66\%, PR 82\%) corresponding to the findings in primary tumours with known involvement of the CNS (68\% ER-negative, $75 \%$ PR-negative). The frequency of HER-2/neu-overexpressing or -amplified cancers was increased in both groups (34 and $32 \%$, respectively). EGFR expression was more frequent in metastases $(41 \%)$ than in primary tumours (16\%). The proportions of cases with a basal phenotype were 26 and $30 \%$, respectively. In paired primary tumours and metastases to the CNS, constancy of Her-2/neu status was observed in $87 \%$ of cases with only one sample turning Her-2/neu-negative and two samples acquiring overexpression/amplification in brain metastases. In contrast, steroid hormone receptors exhibited more frequently a loss of expression (17\%) than a gain (9\%) with $74 \%$ revealing a constant phenotype. We conclude that brain-metastasizing breast cancer belongs predominantly to the basal type or Her-2/neu type. Primary and metastatic tumours differ from each other only in a minority of cases, leading rather to a loss of steroid hormone receptors and to a gain of EGFR and Her-2/neu.
\end{abstract}

Modern Pathology (2007) 20, 864-870; doi:10.1038/modpathol.3800830; published online 1 June 2007

Keywords: brain metastasis; breast cancer; basal phenotype

\section{Introduction}

Breast cancer is the second most common cause of brain metastases. Metastases to the central nervous system (CNS) have long been underestimated. The CNS is a common site of metastasis during the course of breast cancer and is associated with a very unfavourable prognosis. In the past, brain involvement by metastatic breast cancer has been estimated to occur in about $10-16 \%$ of cases, ${ }^{1}$ but recent data indicate an increase of incidence of up to $21 \%$ owing to novel chemotherapies. ${ }^{2-4}$ CNS involvement usually represents a late event during the course

Correspondence: Dr HH Kreipe, MD, Institute of Pathology, Medizinische Hochschule Hannover, Carl-Neuberg-Str. 1, D-30625 Hannover, Germany.

E-mail: Kreipe.Hans@MH-Hannover.de

Received 2 January 2007; revised 16 April 2007; accepted 18 April 2007; published online 1 June 2007 of breast cancer. Increased incidence appears to be attributed to improved diagnostic strategies and a longer overall survival in metastatic breast cancer. $^{2,3,5,6}$ In addition, the higher incidence may be caused by clonal selection induced by novel therapeutic agents like Herceptin. ${ }^{7-10}$ Because diagnostic imaging procedures will usually only be performed after clinical symptoms have become manifest, identification of risk factors for CNS involvement could enable specific surveillance and management of patients at risk. Indicators of an increased risk for CNS metastases have been described such as young age at diagnosis, diseasefree interval less than 1 year, oestrogen receptor (ER) or progesterone receptor (PR) negativity, ${ }^{11}$ and Her$2 /$ neu amplification. ${ }^{9}$ It has only rarely been studied to which degree these adverse biological features are maintained in the metastases proper or whether brain metastases exhibit clonal diversity. 
Case observation studies have suggested that metastatic invasion into the CNS may be the result of clonal selection, favouring Her-2/neu-positive cell clones. ${ }^{12}$ Because elevated protein levels might facilitate the penetration of the blood-brain barrier, it has been assumed that brain metastases, unlike metastases at other locations, might differ significantly from the primary tumours with regard to Her-2/neu expression. ${ }^{12,13}$

In this study, the expression of prognostic markers and of therapeutic target molecules, which are usually analysed in primary tumours, was investigated in CNS metastases of breast cancer.

The aim of the study was to investigate by direct comparison of primary breast cancer and the corresponding CNS metastases a potential clonal evolution leading to divergent expression of therapeutic target molecules. Furthermore, we aimed to elucidate immunohistochemical features of primary breast cancer which could indicate an increased risk for spread to the CNS.

\section{Materials and methods}

From the files of the Institute of Pathology of the Medizinische Hochschule Hannover, anonymized samples from female patients with invasive primary breast cancer and metastasis to the CNS were retrieved. The study was approved by the Local Ethic Committee. Formalin-fixed and paraffin-embedded tissue specimens from 44 primary breast cancer patients and from 85 patients with metastases to the brain were included. In 23 cases, there were mixed pairs with primary breast cancer and corresponding CNS metastasis. In 21 cases of primary breast cancer, there was clinical evidence for brain metastasis but no brain tissue available. All slides were reviewed again and diagnoses were approved.

\section{Tissue Microarray}

On the H\&E-stained slide of the tumour, a representative area was selected and the corresponding spot was marked on the surface of the paraffin block. Using a biopsy needle, the selected area was punched out and the tissue core was put into a commercially available tissue microarray (System Multiblock; Zytomed, Berlin, Germany). The tissue cores were melted together to form a homogeneous new paraffin block that was routinely cut. In comparison to other commercially available tissue arrays, the system used in this study encompasses larger, more representative tissue cores $\left(1.4 \mathrm{~mm}^{2}\right)$ and effectively avoids loss of tissue sections during processing and staining of slides. ${ }^{14}$

\section{Immunohistochemistry}

For immunohistochemical analysis, $2 \mu \mathrm{m}$ tissue sections were mounted on self-coated slides
(poly-L-lysine; Sigma, Deisenhofen, Germany) and stained according to standard protocols. In brief, sections were deparaffined in xylene, rehydrated, and epitope retrieval was performed in a microwave oven, as described previously. ${ }^{15}$ Depending on detection, chromogen endogenous peroxidase or alkaline phosphatase was blocked, and primary antibody was incubated at $4^{\circ} \mathrm{C}$ overnight. The primary antibodies, dilution, and detection method are listed in Table 1.

Detection was carried out using a secondary, biotinylated rabbit-anti-mouse antibody, followed either by incubation with hydroxyperoxidase-linked avidin complex and diaminobenzidine (DAB) as chromogen or by incubation with alkaline phosphatase-labelled streptavidin and fast red (FR) chromogen (Zytomed, Berlin, Germany). Slides were counterstained with Meyer's hemalaun and mounted in immumount (Thermoshandon GmbH; Frankfurt/Main, Germany). The staining was interpreted by two investigators on a multiheaded microscope. Divergent results were discussed, and in case of persistent variability, a third person was consulted.

Scoring of immunostained slides was done according to the percentage of tumour cells exhibiting nuclear (androgen receptor (AR), ER, PR, p27, p53, cyclin D1 and D3, Ki-67, bcl-6), cytoplasmic (annexin, CK5/14, CK14, CK18, CK19, bcl-2), nuclear and cytoplasmic (Skp2), and membrane ( $\beta$-catenin, Ecadherin, epidermal growth factor receptor (EGFR), Her-2/neu) staining. For ER and PR, staining intensity was assessed $(0=$ no staining; $1=$ weak;

Table 1 Primary antibodies

\begin{tabular}{lllll}
\hline Epitope & Clone & Company & Dilution & CS \\
\hline AR & AR 441 & Dako & $1: 250$ & FR \\
Annexin & 29 & TD & $1: 1000$ & DAB \\
$\beta$-Catenin & 14 & TD & $1: 200$ & DAB \\
bcl-2 & 124 & Dako & $1: 150$ & DAB \\
bcl-6 & PG-B6p & Dako & $1: 100$ & FR \\
CK 5/14 & LH8 & CC & $1: 600$ & DAB \\
CK 14 & LL002 & NC & $1: 50$ & DAB \\
CK 18 & DC-10 & NC & $1: 1000$ & DAB \\
CK 19 & BA 17 & Dako & $1: 300$ & DAB \\
Cyclin D1 & DCS-6 & Dako & $1: 50$ & DAB \\
Cyclin D3 & DCS-23 & NC & $1: 25$ & FR \\
ER & 1D5 & Dako & $1: 20$ & DAB \\
E-cadherin & 36 & TD & $1: 2400$ & FR \\
EGFR & C & ZM & $1: 50$ & FR \\
Her-2/neu & Cerb-2 & Dako & $1: 400$ & DAB \\
Ki-67 & Mib-1 & Dako & $1: 250$ & DAB \\
PR & PgR 636 & Dako & $1: 500$ & DAB \\
p27 & SX53GB & Dako & $1: 50$ & DAB \\
p53 & DO-7 & Dako & $1: 200$ & DAB \\
Skp 2 & 2C8D9 & ZM & $1: 80$ & DAB \\
\hline
\end{tabular}

AR, androgen receptor; CC, Chemicon International, Temecula, CA, USA; CK, cytokeratin; CS, chromogen substrate; Dako, DakoCytomation GmbH, Hamburg, Germany; EGFR, epidermal growth factor receptor; ER, oestrogen receptor; NC, Novo Casta, Newcastle, UK; PR, progesterone receptor; TD, Transduction Laboratories, Lexington, KY, USA; ZM, Zytomed, Berlin, Germany. 
$2=$ moderate; and $3=$ strong). ER and PR were evaluated using Remmele's Immunoreactive Score by multiplying staining intensity (as described above) and percentage of tumour cells $(0 \leq 10 \%$; $1=10-50 \% ; 2=51-80 \% ; 3 \geq 80 \%$ positive tumour cells). Scores below 4 were considered steroid hormone receptor negative. Her-2/neu staining was scored according to the DAKO guidelines suggested for the HercepTest using the following categories: 0 , negative result or membrane staining in $<10 \%$ tumour cells; $1+$ weak and incomplete membrane staining in $>10 \%$ tumour cells; $2+$ weak or moderate, complete staining in $>10 \%$ tumour cells; $3+$ strong complete membrane staining in $>10 \%$ tumour cells. Zero or $1+$ represented a negative Her-2/neu staining result, whereas $3+$ was considered positive. Two positive cases were evaluated as positive only when fluorescence in situ hybridization (FISH) revealed amplification of the gene. Specimens were considered positive for cytokeratins (CKs) 5/14, 14, 18, 19 when at least $5 \%$ of tumour cells were stained. For AR, annexin, p53, p27, and $\beta$-catenin, $50 \%$ were required. Bcl-2, EGFR and E-cadherin were categorised into negative, weak, and strong-positive. Different thresholds were applied 10\% (EGFR, E-cadherin, Skp 2, bcl6), 30\% (bcl2), and $50 \%$ ( $\beta$-catenin). Proliferation markers Ki-67, cyclin D1, and cyclin D3 were evaluated semiquantitatively and rounded to $5 \%$ steps.

\section{FISH}

FISH analysis of the Her-2/neu gene was performed following a standardized protocol. ${ }^{16}$ In brief, the sections from tissue micro arrays were mounted on Superfrost Plus slides, deparaffined in xylene, and subsequently, rehydrated. Afterwards they were boiled for $30 \mathrm{~min}$ in $6 \mathrm{M}$ Sodium-citrate buffer, incubated with pepsin solution for $5 \mathrm{~min}$, incubated another $10 \mathrm{~min}$ in paraformaldehyde, and finally airdried. For hybridization, the buffered probe (Her-2/ neu and centromer 17) was brought onto the slide and protected by a coverslip, which was sealed with rubber cement. For denaturation, slides were heated to $80^{\circ} \mathrm{C}$ and incubated overnight at $37^{\circ} \mathrm{C}$ in a humidified dark chamber. Afterwards, the rubber cement and the coverslip were removed and the slides were counterstained with 4',6-diamidino-2phenylindole (DAPI). Finally, a drop of Vectashield antifade (Vector, Odessa, FL, USA) was added and covered with another coverslip. Evaluation of signals was carried out using an epifluorescence microscope (Axioskop 2, Zeiss, Oberkochen, Germany) equipped with a fluorescein, Сy3 and DAPI filter set, and a 100-W mercury lamp. The counting was carried out according to the Vysis manual, where Her-2/neu gene appeared as orange signal, and centromer 17 as green one. In each tumour, at least 50 nuclei were evaluated and the Her-2/neu gene was considered to be amplified if ratio (Her-2/neu signals/centromer 17 signals) reached 2.0 or higher.

\section{Statistical Analysis}

Data were statistically processed using SPSS for Windows Version 11.5. 1 (SPSS Inc., Chicago, IL, USA). Correlation analyses of immunostaining (primary breast cancer versus CNS metastasis) were calculated by using Wilcoxon test. Cluster analyses were conducted by hierarchical cluster analysis using Euclidean distance and single linkage. Other distances or agglomerative measures gave very similar results (data not shown). Percentages were rounded off to nearest integer.

\section{Results}

\section{Brain Metastases of Breast Cancer}

In 85 samples from intracerebral metastases from breast cancer, the Her-2/neu-overexpressing or -amplified phenotype was encountered in 29 cases (34\%). In comparison to the proportion of Her-2/ neu-positive cases among all primary breast cancers diagnosed in our institution (20\%), Her-2/neupositive breast cancers were clearly overrepresented in brain metastases. The basal phenotype as defined by positivity for basal CKs, steroid hormone receptor negativity, missing Her-2/neu-overexpression and/ or positivity for EGFR was found in 22 cases (26\%). The proportion of breast cancer patients belonging to the basal type category ranges from 10 to $18 \%$ in the literature, demonstrating a higher incidence in brain metastases. Whereas in total breast cancers, only $15-20 \%$ of cases are negative for steroid hormone receptors, more than $64 \%$ were found to be negative for both receptors in this cohort. Oestrogen receptor negativity was seen in $66 \%$ of cases and PR negativity in $82 \%$ (Table 2).

With regard to the proliferative activity as determined by the Ki-67 labelling index, the median was $25 \%$. In brain metastases, more than $57 \%$ of cases exhibited the highly proliferating phenotype with more than $25 \%$ of cells being in the cycle. Among breast cancers investigated in our institution, the median is between 15 and $20 \%$ and only about $35 \%$ belong to the highly proliferating phenotype with Ki-67 labelling index exceeding 25\% (Table 3).

\section{Primary Breast Cancers with Known Brain Involvement}

From 44 cases of primary breast cancer, onset of metastasis to the brain during the course of the disease was documented and these cases also entered the study. In this group of cancer patients, the Her-2/neu-overexpressing or -amplified subtype made up $32 \%(n=14)$, corresponding to the overrepresentation observed in brain metastases. The 
latter also hold true for the basal phenotype $(n=14$; $32 \%)$. Primary tumours differed from CNS metastases when EGFR expression was considered. In this respect, while $41 \%$ of metastases revealed positivity but only $16 \%$ of primary tumours revealed positivity. The percentage of steroid hormone receptornegative cases paralleled the findings in metastatic brain infiltrates. ER negativity was found in $68 \%$ of cases $(n=30)$ and only $25 \%(n=11)$ were expressing the PR receptor (Table 2). When the proliferative activity was considered, the highly proliferating subtype with Ki-67 $>25 \%$ made up the majority of cases $(n=22 ; 50 \%$; Table 3$)$.

\section{Paired Primary Tumours and Brain Metastases}

Both cohorts described above overlapped in 23 cases allowing direct comparison of the primary tumour

Table 2 Steroid hormone receptors, cytokeratins, and adhesion molecules in primary breast cancer with known involvement of the brain and CNS metastases from breast cancer

\begin{tabular}{|c|c|c|c|c|}
\hline & \multicolumn{2}{|c|}{$\begin{array}{l}\text { Primary breast cancer } \\
\qquad(\mathrm{n}=44)^{a}\end{array}$} & \multicolumn{2}{|c|}{$\begin{array}{l}\text { CNS metastases } \\
\qquad(\mathrm{n}=85)^{a}\end{array}$} \\
\hline & $\begin{array}{l}\text { Positive } \\
(\%)\end{array}$ & $\begin{array}{l}\text { Negative } \\
(\%)\end{array}$ & $\begin{array}{l}\text { Positive } \\
(\%)\end{array}$ & $\begin{array}{c}\text { Negative } \\
(\%)\end{array}$ \\
\hline \multicolumn{5}{|l|}{ Receptors } \\
\hline ER & $14(32)$ & $30(68)$ & $29(34)$ & $56(66)$ \\
\hline PR & $11(25)$ & $33(75)$ & $15(18)$ & $70(82)$ \\
\hline Her-2/neu & $14(32)$ & $30(68)$ & $29(34)$ & $56(66)$ \\
\hline EGFR & 7 (16) & $37(84)$ & $35(41)$ & $50(59)$ \\
\hline \multicolumn{5}{|l|}{ Cytokeratins } \\
\hline CK 5/14 & $13(30)$ & $31(70)$ & $22(26)$ & $61(74)$ \\
\hline CK 18 & $29(67)$ & $14(32)$ & $82(98)$ & $2(2)$ \\
\hline CK 19 & $43(100)$ & 0 & $80(96)$ & $3(4)$ \\
\hline \multicolumn{5}{|c|}{ Adhesion molecules } \\
\hline E-cadherin & $35(83)$ & 7 (17) & $76(90)$ & $8(10)$ \\
\hline$\beta$-Catenin & 37 (86) & $6(14)$ & $64(76)$ & $20(34)$ \\
\hline
\end{tabular}

CK, cytokeratin; EGFR, epidermal growth factor receptor; ER, oestrogen receptor; PR, progesterone receptor.

${ }^{\mathrm{a}}$ Some of the markers were applied to one or two samples less than the complete series. and the corresponding metastases. As suggested already by the very similar immunohistochemical profiles of both cohorts, the majority of cases revealed stable marker expression. Constancy of Her-2/neu status was observed in $87 \%(n=20)$. Only one sample turned Her-2/neu-negative. In two samples $(9 \%)$, a newly acquired amplification was detected. In one case with an aberrant status, antiHer-2/neu therapy with monoclonal antibody had been administered, no change of Her-2/neu status could be observed in this case (Table 4). Considering EGFR, a gain of expression could be observed in five cases $(23 \%)$.

With regard to cell cycle parameters and apoptosis, there was no obvious change with the exception of Skp2, which was expressed to a significantly higher level in brain metastasis $(P<0.024$; Table 5). A change of phenotype was observed more frequently when steroid hormone receptor expression was considered. About $74 \%$ of cases $(n=17)$

Table 4 Steroid hormone receptors, cytokeratins, and adhesion molecules in paired samples from primary breast cancer and CNS metastases

\begin{tabular}{|c|c|c|c|c|}
\hline & \multicolumn{2}{|c|}{$\begin{array}{l}\text { Primary cancer } \\
\qquad(\mathrm{n}=23)^{a}\end{array}$} & \multicolumn{2}{|c|}{$\begin{array}{l}\text { Metastases } \\
(\mathrm{n}=23)^{a}\end{array}$} \\
\hline & Positive & Negative & Positive & Negative \\
\hline \multicolumn{5}{|l|}{ Receptors } \\
\hline ER & 11 & 12 & 9 & 14 \\
\hline PR & 6 & 17 & 5 & 18 \\
\hline Her-2/neu & 8 & 15 & 10 & 13 \\
\hline EGFR & 3 & 20 & 8 & 15 \\
\hline \multicolumn{5}{|l|}{ Cytokeratins } \\
\hline CK $5 / 14$ & 5 & 18 & 6 & 15 \\
\hline CK 18 & 15 & 7 & 22 & 0 \\
\hline \multicolumn{5}{|c|}{ Adhesion molecules } \\
\hline E-cadherin & 21 & 0 & 21 & 1 \\
\hline$\beta$-Catenin & 20 & 2 & 20 & 2 \\
\hline
\end{tabular}

CK, cytokeratin; EGFR, epidermal growth factor receptor; ER, oestrogen receptor; PR, progesterone receptor.

${ }^{\mathrm{a}}$ Some of the markers were applied to only 21 or 22 samples.

Table 3 Expression of markers of proliferation and apoptosis in primary breast cancer with known involvement of the brain and CNS metastases from breast cancer

\begin{tabular}{|c|c|c|c|}
\hline Marker (threshold) & $\begin{array}{c}\text { Primary } / \text { metastases } \\
\text { Mean }\end{array}$ & $\begin{array}{c}\text { Primary/metastases } \\
\text { Median }\end{array}$ & $\begin{array}{c}\text { Primary/metastases } \\
\text { Above threshold }\end{array}$ \\
\hline \multicolumn{4}{|l|}{ Proliferation } \\
\hline Ki 67 (>25\%) & $24.9 / 30.0$ & $25 / 25$ & $22(50 \%) / 47(55 \%)$ \\
\hline Skp $2(>10 \%)$ & $6 / 13.4$ & $2.5 / 2.5$ & $4(10 \%) / 27(32 \%)$ \\
\hline p27 (>50\%) & $47 / 49.2$ & $45 / 55$ & $21(48 \%) / 46(54 \%)$ \\
\hline Cyclin D1 (>10\%) & $17.7 / 19.7$ & $2.5 / 7.5$ & $17(39 \%) / 41(48 \%)$ \\
\hline Cyclin D3 $(>10 \%)$ & $29.8 / 17.7$ & $15 / 7.5$ & $26(59 \%) / 34(40 \%)$ \\
\hline \multicolumn{4}{|l|}{ Apoptosis } \\
\hline bcl $6(>10 \%)$ & $14.7 / 22.4$ & $2.5 / 7.5$ & $12(27 \%) / 38(45 \%)$ \\
\hline bcl 2 (>30\%) & $25.8 / 23.5$ & $2.5 / 2.5$ & $21(48 \%) / 24(28 \%)$ \\
\hline
\end{tabular}


exhibited constant expression. For ER, loss of expression was found in four cases $(17 \%)$ and gains were encountered in two cases $(9 \%)$. The numbers were almost identical for PR except for one case, where the loss was less (Table 4). Interestingly, there was an induction of CK 18 expression in brain metastases $(P=0.001)$. With regard to the proliferative activity, more than $61 \%$ of cases retained the feature of high proliferative activity which got lost in $17 \%$ of cases. Whereas cyclin D1 expression appeared to be increased in brain metastases cyclin D3 was reduced $(P=0.035$; Table 5$)$.

All changes between primary tumours and brain metastases are summarized in Table 6.

\section{Discussion}

The incidence of CNS metastases in breast cancer is increasing. Depending on the type of study, the percentage of breast cancer involving the brain ranges from 10 to $40 \%$; and there appears to be a tendency to underestimate the incidence. The increase may be due to more effective treatments prolonging survival of patients with metastatic disease to extracerebral sites and also to more accurate methods of detection, such as magnetic resonance imaging.

Previous reports delineated clinical risk factors that indicate a higher incidence of metastasis to the CNS. Only $5 \%$ of patients with ER-positive primary tumours developed CNS metastases, whereas $9 \%$ of patients with ER-negative tumours developed CNS metastases. ${ }^{17}$ Also, brain metastases appear to be associated with younger age. ${ }^{1,17}$ Only a limited number of patho-anatomical studies on the brainmetastasizing type of breast cancer has been undertaken and even fewer studies of human CNS metastases are available because only a small percentage of affected patients undergo surgery. ${ }^{8,18,19}$ Lear-Kaul et a ${ }^{19}$ investigated Her-2/neu expression/ amplification in nine paired cases of brain-metastasizing breast cancer and showed CNS metastases to reflect widely the status of the primary tumour. In contrast, EGFR expression exhibited a higher degree of diversity between primary cancer and brain metastasis with concordance in only 8 out of 11 patients $(73 \%){ }^{20}$ In another study, p53, bcl-2, Ecadherin, MMP-Y, and EGFR were analysed but no significant changes could be detected. ${ }^{18}$

In this study, a cohort of brain metastases from breast cancer and a cohort of primary breast cancers, which developed CNS metastases during the course of the disease were studied. Both groups revealed a similar profile of risk factors. Whereas steroid hormone receptor-negative cases make up only 15$20 \%$ in total breast cancers, ${ }^{21}$ but in brain-metastasizing breast cancer of this study, $64 \%$ were negative for ER and PR. Steroid hormone receptor negativity is known to be associated with an unfavourable and aggressive course. ${ }^{22}$ Recently, using RNA expression profiles, the basal phenotype of breast cancer representing a particularly unfavourable type of cancer has been identified. ${ }^{23}$ The proportion of breast cancers exhibiting a basal phenotype with expression of basal CKs is about $10-18 \%$ when detected by means of immunohistochemistry. ${ }^{24-26} \mathrm{In}$ the two cohorts of brain-metastasizing breast cancer under study, the basal phenotype was clearly overrepresented encompassing $27 \%$ of all samples (Table 2).

Another prognostic adverse feature is provided by Her-2/neu overexpression or amplification, which

Table 6 Changes of marker expression in paired samples from primary breast cancer and CNS metastases $(n=23)^{\mathrm{a}}$

\begin{tabular}{lcrrrr}
\hline Primary/metastasis & Constant & $+/+$ & $-/-$ & Gain & Loss \\
\hline ER & $17(74 \%)$ & 7 & 10 & 2 & 4 \\
PR & $18(78 \%)$ & 3 & 15 & 2 & 3 \\
Her-2/neu & $20(87 \%)$ & 8 & 12 & 2 & 1 \\
EGFR & $18(78 \%)$ & 3 & 15 & 5 & 0 \\
CK 5/14 & $17(77 \%)$ & 3 & 14 & 4 & 1 \\
CK 18 & $14(67 \%)$ & 14 & 0 & 7 & 0 \\
Ki-67 (>25\%) & $14(61 \%)$ & 6 & 8 & 5 & 4 \\
Skp 2 (>10\%) & $15(71 \%)$ & 0 & 15 & 5 & 1
\end{tabular}

CK, cytokeratin; EGFR, epidermal growth factor receptor; ER, oestrogen receptor; PR, progesterone receptor.

${ }^{\mathrm{a}}$ Some of the markers were applied to only 21 or 22 samples.

Table 5 Expression of markers of proliferation and apoptosis in paired samples from primary breast cancer and CNS metastases

\begin{tabular}{|c|c|c|c|}
\hline Marker (threshold) & $\begin{array}{c}\text { Primary/metastasis } \\
\text { Mean }\end{array}$ & $\begin{array}{c}\text { Primary/metastasis } \\
\text { Median }\end{array}$ & $\begin{array}{l}\text { Primary/metastasis } \\
\text { Above threshold }\end{array}$ \\
\hline \multicolumn{4}{|l|}{ Proliferation } \\
\hline Ki-67 (>25\%) & $25.7 / 26.5$ & $15.0 / 30.0$ & $10(44 \%) / 11(48 \%)$ \\
\hline Skp $2(>10 \%)$ & $3.0 / 9.5$ & $2.5 / 2.5$ & $1(5 \%) / 6(28 \%)$ \\
\hline p27 (>50\%) & $57.3 / 58.7$ & $60.0 / 65.0$ & $14(61 \%) / 15(65 \%)$ \\
\hline Cyclin D1 (>10\%) & $19.4 / 28.2$ & $2.5 / 25.0$ & $9(39 \%) / 15(65 \%)$ \\
\hline Cyclin D3 $(>10 \%)$ & $46.9 / 24.6$ & $45.0 / 15.0$ & $18(78 \%) / 15(65 \%)$ \\
\hline \multicolumn{4}{|l|}{ Apoptosis } \\
\hline bcl $6(>30 \%)$ & $25.8 / 12.6$ & $11.3 / 7.5$ & $10(43 \%) / 8(35 \%)$ \\
\hline bcl $2(>10 \%)$ & $28.6 / 29.5$ & $15.0 / 2.5$ & $15(65 \%) / 8(35 \%)$ \\
\hline
\end{tabular}


also became evident from gene expression studies. ${ }^{23}$ Furthermore, recent studies reported an increased incidence of brain metastases in Her-2/neu-positive breast cancers. The reasons for the increased incidence are not yet clear. It may be caused either by a failure of receptor-blocking therapy at this anatomical site, ${ }^{8}$ or by a high intrinsic propensity of amplified cancers to metastasize in the CNS. ${ }^{27}$ In the current series, only one patient who received antibody therapy was included. In this case, no change of expression was observed. Her-2/neu-overexpressing cases were clearly overrepresented in brainmetastasizing breast cancer of this study pointing to a higher intrinsic risk. The percentage of Her-2/neuoverexpressing or -amplified cases in both cohorts was $33 \%$ exceeding the overall incidence of Her-2/ neu aberrant cases, which is $20 \%$ in our institution and between 18 and $25 \%$ in the literature. ${ }^{28-30} \mathrm{In}$ $40 \%$ of cases, which neither belonged to Her-2/neu overexpressing category nor to the basal phenotype exhibited, a high proliferative capacity was found. The median Ki-67 index was $25 \%$. In all breast cancer types, the median proliferation index is considerably lower. ${ }^{31}$

Intratumoural heterogeneity provides a hallmark of malignant neoplasm. Therefore, it is an open issue whether subclonal diversity can be reflected reliably by a single biopsy or section from steadily shrinking cancer specimens down to the size of core biopsies in the neoadjuvant setting. In direct comparison of CNS metastasis with primary tumours as done in this study, we found evidence that subclones, which will give rise to brain metastasis and which are characterized by overexpression of Her-2/neu may be missed. The proportion of such discrepancies, however, is comparably small and affects only a minority of cases. With regard to Her2/neu, diverse expression patterns were encountered in only $13 \%$ of cases. Previous reports described different degrees of concordance between primary tumour and distant metastases. In these studies, 4 to 13 cases with brain metastasis were investigated. In most studies, concordance between primary tumour and distant metastases ranged between 87 and $100 \% .^{32-36}$ Regitnig et al ${ }^{13}$ found a newly occurring Her-2/neu amplification in metastases in 4 out of 18 cases $(22 \%), 2$ of which represented CNS metastases. In their series, Her-2/ neu-amplified primary tumours made up $14 \%$ of cases in the paired samples, which is different from our series consisting of brain-metastasizing tumours only.

Interestingly, EGFR expression revealed a higher degree of variability between primary tumours and brain metastases (Tables 2 and 6). EGFR is reportedly overexpressed in $15-20 \%$ of breast carcinomas, ${ }^{37}$ which is in the range found in this series of primary tumours. In brain metastases, however, the incidence was found to be higher ranging to $41 \%$. Coexpression of EGFR and Her-2/neu was observed in 10 cases. Unlike Her-2/neu, EGFR overexpression is only rarely associated with gene amplification. ${ }^{38}$ Whether increased EGFR labelling of metastases represents intraclonal selection or induction by the local environment within the brain cannot be determined at present.

Change in the expression of steroid hormone receptor expression has been reported before on other sites of distant metastases, but not in the brain. ${ }^{39,40}$ Cluster analyses of 23 primary breast cancer and corresponding metastases cases using all immunohistochemical markers applied in this study revealed a close similarity between primary and metastatic tumours but no systematic difference between primary and secondary metastatic tumour manifestations (data not shown).

Our data provide evidence that a subgroup of primary breast cancers can be identified which carry an increased risk to metastasize to the brain. In the majority of cases, the phenotype present in the intracerebral metastasis is already manifested in the primary tumour. Whether tumour patients with a risk profile for brain metastases should receive special surveillance to detect early and occult brain metastases ${ }^{27}$ will have to be studied further.

\section{Acknowledgements}

We thank H Gerlings for statistical analysis and L Wingen for performing cluster analysis. Many data were provided by Dr G Wegener, Tumorzentrum of the MHH. This work is supported by Deutsche Krebshilfe Grant 70-3121-Kr1.

\section{References}

1 Lin NU, Bellon JR, Winer EP. CNS metastases in breast cancer. J Clin Oncol 2004;22:3608-3617.

2 Crivellari D, Pagani O, Veronesi A, et al. High incidence of central nervous system involvement in patients with metastatic or locally advanced breast cancer treated with epirubicin and docetaxel. Ann Oncol 2001;12:353-356.

3 Ryberg M, Nielsen D, Osterlind K, et al. Predictors of central nervous system metastasis in patients with metastatic breast cancer. A competing risk analysis of 579 patients treated with epirubicin-based chemotherapy. Breast Cancer Res Treat 2005;91:217-225.

4 Abali H, Celik I. High incidence of central nervous system involvement in patients with breast cancer treated with epirubicin and docetaxel. Am J Clin Oncol 2002;25:632-633.

5 Ahmann FR, Jones SE, Moon TE. The effect of prior adjuvant chemotherapy on survival in metastatic breast cancer. J Surg Oncol 1988;37:116-122.

6 Kosmas C, Malamos NA, Tsavaris NB, et al. Leptomeningeal carcinomatosis after major remission to taxanebased front-line therapy in patients with advanced breast cancer. J Neuro Oncol 2002;56:265-273.

7 Bendell JC, Domchek SM, Burstein HJ, et al. Central nervous system metastases in women who receive trastuzumab-based therapy for metastatic breast carcinoma. Cancer 2003;97:2972-2977. 
8 Weil RJ, Palmieri DC, Bronder JL, et al. Breast cancer metastasis to the central nervous system. Am J Pathol 2005;167:913-920.

9 Duchnowska R, Szczylik C. Central nervous system metastases in breast cancer patients administered trastuzumab. Cancer Treat Rev 2005;31:312-318.

10 Clayton AJ, Danson S, Jolly S, et al. Incidence of cerebral metastases in patients treated with trastuzumab for metastatic breast cancer. Br J Cancer 2004; 91:639-643.

11 Maki DD, Grossman RI. Patterns of disease spread in metastatic breast carcinoma: influence of estrogen and progesterone receptor status. Am J Neuroradiol 2000; 21:1064-1066.

12 Montemurro F, Sarotto I, Casorzo L, et al. HER2 and central nervous system metastasis in patients with breast cancer. Clin Breast Cancer 2004;5 232-234.

13 Regitnig P, Schippinger W, Lindbauer M, et al. Change of HER-2/neu status in a subset of distant metastases from breast carcinomas. J Pathol 2004;203:918-926.

14 Von Wasielewski R, Mengel M, Wiese B, et al. Tissue array technology for testing interlaboratory and interobserver reproducibility of immunohistochemical estrogen receptor analysis in a large multicenter trial. Am J Clin Pathol 2002;118:675-682.

15 Von Wasielewski R, Werner M, Nolte M, et al. Effects of antigen retrieval by microwave heating in formalinfixed tissue sections on a broad panel of antibodies. Histochemistry 1994;102:165-172.

16 Wilkens L, Gerr H, Gadzicki D, et al. Standardised fluorescence in situ hybridisation in cytological and histological specimens. Virchows Arch 2005;447: 586-592.

17 Evans AJ, James JJ, Cornford EJ, et al. Brain metastases from breast cancer: identification of a high-risk group. Clin Oncol (R Coll Radiol) 2004;16:345-349.

18 Arnold SM, Young AB, Munn RK, et al. Expression of p53, bcl-2, E-cadherin, matrix metalloproteinase-9, and tissue inhibitor of metalloproteinases-1 in paired primary tumors and brain metastasis. Clin Cancer Res 1999;5:4028-4033.

19 Lear-Kaul KC, Yoon HR, Kleinschmidt-DeMasters BK, et al. Her-2/neu status in breast cancer metastases to the central nervous system. Arch Pathol Lab Med 2003;127:1451-1457.

20 Grupka NL, Lear-Kaul KC, Kleinschmidt-DeMasters $\mathrm{BK}$, et al. Epidermal growth factor receptor status in breast cancer metastases to the central nervous system. Comparison with HER-2/neu status. Arch Pathol Lab Med 2004;128:974-999.

21 Allred DC, Harvey JM, Berardo M, et al. Prognostic and predictive factors in breast cancer by immunohistochemical analysis. Mod Pathol 1998;11:155-168.

22 Goldhirsch A, Glick JH, Gelber RD, et al. Meeting highlights: international expert consensus on the primary therapy of early breast cancer 2005. Ann Oncol 2005;16:1569-1583.

23 Perou CM, Sorlie T, Eisen MB, et al. Molecular portraits of human breast tumours. Nature 2000;406: 747-752.

24 Rakha EA, Putti TC, Abd El-Rehim DM, et al. Morphological and immunophenotypic analysis of breast carcinomas with basal and myoepithelial differentiation. J Pathol 2006;208:495-506.

25 Laakso M, Tanner M, Nilsson J, et al. Basoluminal carcinoma: a new biologically and prognostically distinct entity between basal and luminal breast cancer. Clin Cancer Res 2006;12:4185-4191.

26 Nielsen TO, Hsu FD, Jensen $\mathrm{K}$, et al. Immunohistochemical and clinical characterization of the basal-like subtype of invasive breast carcinoma. Clin Cancer Res 2004;10:5367-5374.

27 Miller KD, Weathers T, Haney LG, et al. Occult central nervous system involvement in patients with metastatic breast cancer: prevalence, predictive factors and impact on overall survival. Ann Oncol 2003;14: 1072-1077.

28 Borg A, Tandon AK, Sigurdsson H, et al. HER-2/neu amplification predicts poor survival in node-positive breast cancer. Cancer Res 1990;50:4332-4337.

29 Yamashita H, Nishio M, Toyama T, et al. Coexistence of HER2 over-expression and p53 protein accumulation is a strong prognostic molecular marker in breast cancer. Breast Cancer Res 2004;6:R24-R30.

30 Ross JS, Fletcher JA. HER-2/neu (c-erb-B2) gene and protein in breast cancer. Am J Clin Pathol 1999; 112(1 Suppl 1):S53-S67.

31 Gerdes J, Lelle RJ, Pickartz H, et al. Growth fractions in breast cancers determined in situ with monoclonal antibody Ki-67. J Clin Pathol 1986;39:977-980.

32 Niehans GA, Singleton TP, Dykoski D, et al. Stability of HER-2/neu expression over time and at multiple metastatic sites. J Natl Cancer Inst 1993;85:1230-1235.

33 Shimizu C, Fukutomi T, Tsuda H, et al. c-erbB-2 protein overexpression and p53 immunoreaction in primary and recurrent breast cancer tissues. J Surg Oncol 2000;73:17-20.

34 Tanner M, Jarvinen P, Isola J. Amplification of HER-2/ neu and topoisomerase IIalpha in primary and metastatic breast cancer. Cancer Res 2001;61:5345-5348.

35 Gancberg D, Di Leo A, Cardoso F, et al. Comparison of HER-2 status between primary breast cancer and corresponding distant metastatic sites. Ann Oncol 2002;13:1036-1043.

36 Alex B, Jamal Z, Igor D, et al. Evaluation of HER-2 in primary breast cancer and metastatic sites. Proc Am Soc Clin Oncol 2002;21.

37 Bossuyt V, Fadare O, Martel M, et al. Remarkably high frequency of EGFR expression in breast carcinomas with squamous differentiation. Int J Surg Pathol 2005; 13:319-327.

38 Umemura S, Takekoshi S, Suzuki Y, et al. Estrogen receptor-negative and human epidermal growth factor receptor 2-negative breast cancer tissue have the highest Ki-67 labeling index and EGFR expression: gene amplification does not contribute to EGFR expression. Oncol Rep 2005;14:337-343.

39 Umekita Y, Sagara Y, Yoshida H. Estrogen receptor mutations and changes in estrogen receptor and progesterone receptor protein expression in metastatic or recurrent breast cancer. Jpn J Cancer Res 1998;89:27-32.

40 Johnston SR, Saccani-Jotti G, Smith IE, et al. Changes in estrogen receptor, progesterone receptor, and pS2 expression in tamoxifen-resistant human breast cancer. Cancer Res 1995;55:3331-3338. 